Bond University

Research Repository

\title{
Smoking and psychological health in relation to country of origin
}

\author{
Lyvers, Michael; Hall, Tessa; Bahr, Mark
}

Published in:

International Journal of Psychology

DOI:

$10.1080 / 00207590802511759$

Licence:

Other

Link to output in Bond University research repository.

Recommended citation(APA):

Lyvers, M., Hall, T., \& Bahr, M. (2009). Smoking and psychological health in relation to country of origin. International Journal of Psychology, 44(5), 387-392. https://doi.org/10.1080/00207590802511759

\footnotetext{
General rights

Copyright and moral rights for the publications made accessible in the public portal are retained by the authors and/or other copyright owners and it is a condition of accessing publications that users recognise and abide by the legal requirements associated with these rights.
}

For more information, or if you believe that this document breaches copyright, please contact the Bond University research repository coordinator. 


\section{Bond University}

\section{ePublications@bond}

9-2009

\section{Smoking and psychological health in relation to country of origin}

Michael Lyvers

Bond University, michael_lyvers@bond.edu.au

Tessa Hall

Bond University

Mark Bahr

Bond University, Mark_Bahr@bond.edu.au

Follow this and additional works at: http://epublications.bond.edu.au/hss_pubs

Part of the Health Psychology Commons, and the Personality and Social Contexts Commons

\section{Recommended Citation}

Michael Lyvers, Tessa Hall, and Mark Bahr. (2009) "Smoking and psychological health in relation to country of origin" International journal of psychology, 44 (5), 387-392.

http://epublications.bond.edu.au/hss_pubs/255 
Smoking and Psychological Health in Relation to Country of Origin Michael Lyvers, Ph.D.

Tessa Hall, Postgraduate Diploma of Psychology

Mark Bahr, Ph.D.

Department of Psychology

Bond University

Gold Coast, Queensland 4229

Australia

Address correspondence to:

Michael Lyvers

Associate Professor of Psychology

Bond University

Gold Coast, Queensland 4229

Australia

Phone: 61755952565

Fax: 61755952540

Email: mlyvers@staff.bond.edu.au 


\begin{abstract}
In English-speaking, Western-Anglo countries, where smoking has become stigmatized in recent decades as a result of widespread anti-smoking campaigns, smokers commonly report poorer psychological health on average than non-smokers do. This may be indirectly related to the strong pressures to quit in such countries, as poorer psychological health is associated with a reduced likelihood of quitting, thus leading to a selection bias for smokers with relatively poorer psychological health. In the present study, 147 smoker and non-smoker participants either came from Western-Anglo countries where smoking has become stigmatized (Australia, Canada, U.S.) or countries in regions where smoking remains relatively more accepted (Asia, Latin America, Europe). Smokers and non-smokers were assessed on a widely used self-report measure of anxiety, depression, and stress. Multivariate analysis revealed a significant interaction between smoker status (smoker, non-smoker) and country of origin (Western-Anglo, Other) on psychological health ratings, with univariate analysis showing a significant interaction on anxiety scores. Among those from WesternAnglo countries, smokers reported significantly higher levels of anxiety than non-smokers did, whereas there was no difference in anxiety between smokers and non-smokers from other countries. There was no difference in number of cigarettes smoked per day between the samples of smokers, indicating very similar levels of nicotine intake in the two groups. The findings support the notion that a selection bias for smokers with relatively poorer psychological health is occurring in Western-Anglo countries.
\end{abstract}

KEYWORDS: smoking, anxiety, stress, culture 
Despite the fact that tobacco smoking kills more people each year than AIDS, alcohol, drug abuse, car crashes, murders, suicides and fires combined, approximately one-third of the world adult population still smokes (Centers for Disease Control and Prevention, CDC, 2004). Tobacco smoking is thus arguably one of the most alarming health issues facing any nation today. In response, aggressive anti-smoking media campaigns have been ubiquitous in English-speaking countries such as the U.S., Canada and Australia over the last two decades (Chassin, Presson, Sherman \& Kim, 2003), and research on the effects of tobacco smoking has been prolific with several empirical journals dedicated specifically to tobacco smoking research. Investigations into the power of antismoking campaigns to induce negative social attitudes towards smoking (Hersey et al, 2005) and to lower smoking prevalence rates (McVey \& Stapleton, 2000) have shown them to be effective on both counts. The heavy campaigning in Western-Anglo nations such as the U.S., Canada and Australia has thus been credited at least partially for increasing quit rates and decreasing smoking prevalence (Pierce, Gilpin \& Emery, 1998).

Results from the Australian 2001 National Drug Strategy Household Survey (AIHW, 2002) revealed that among people over 14 years old, approximately 19.5\% smoked daily. This was the first recorded time the prevalence rate dropped below $20 \%$, with $21 \%$ of males and $18 \%$ of females being daily smokers. Although quit rates in Australia and the U.S. have steadily risen from the 1970’s through to the 1990’s (Hughes, 1993; Victorian Smoking and Health Program Australia, 1995), the rates slowed and reached a plateau over the last decade (Mitchell \& Sanders, 2004). The plateau of smoking prevalence may be attributable to several factors. Trosclair, Husten, Pederson, and Dhillon (2002) reported that despite the plethora of health warnings and social sanctions, approximately half of smokers never quit. Hughes and Brandon (2003) claimed that causally important differences must exist between the smokers who quit and those who do not. Perhaps smokers who are more resistant to quitting in the face 
of anti-smoking campaigning and social pressure have distinctive characteristics compared to those who do manage to quit. A selection bias that has filtered the quitters from the recalcitrant smokers may be causing the current plateau in smoking prevalence as well as the commonly reported association between smoking and relatively poorer psychological health. Several studies have reported that smokers tend to report higher levels of anxiety and/or stress than non-smokers do, and co-morbid anxiety or depression is associated with a significant reduction in the likelihood of quitting (Grant, Hasin, Chou, Stinson \& Dawson, 2004; Parrott, 2006; Schumann, Hapke, Meyer, Rumpf, \& Ulrich, 2004; Schmitz, Kruse \& Krugler, 2003). Such studies were conducted in countries with relatively low and historically declining rates of smoking in response to strong anti-smoking campaigns. By contrast, an exploratory study by Lyvers, Thorberg, Dobie, Huang, and Reginald (2006) compared smokers and nonsmokers from Western-Anglo and East Asian countries on self-report measures of psychological health, finding that although as predicted Western smokers were significantly more anxious than Western non-smokers, this was not the case for East Asians, among whom smoking is more socially and culturally accepted. Less than one quarter of the population of the Western-Anglo countries sampled (Australia, Canada, and the U.S.) smoke according to World Health Organization (WHO) statistics, whereas Chinese and Japanese smoking prevalence rates are considerably higher, especially for males (67\% and 53\% respectively); in addition, U.S. quit rates are around $42 \%$ whereas Chinese quit rates are around $10 \%$ (WHO Tobacco Atlas, 2002). The preliminary findings of Lyvers et al. thus may reflect a selection bias operating in the Western-Anglo countries because smokers who are more prone to dysphoric states are less likely to quit (presumably due to the anxiolytic and antidepressantlike effects of nicotine), therefore the population of remaining smokers may gradually become more anxious or depressed on average than the non-smoking population. 
The current study expanded on the previous findings by comparing smokers and nonsmokers from Western-Anglo backgrounds as well as those from diverse other countries on self-reported anxiety, stress, and depression to test the hypothesis that a selection bias driven by mental health and self efficacy to quit is shaping smoker populations in Western-Anglo countries, where smoking has become stigmatized as a result of strong anti-smoking campaigns. Participants were recruited from an Australian university that has a high proportion of exchange students from overseas. For the purposes of this study, students' countries of origin were classed as either (1) Western-Anglo countries where smoking is stigmatized and less than one quarter of the population smokes according to WHO statistics (WHO Tobacco Atlas, 2002), or (2) relatively more smoker-friendly countries in Asia, Latin America, the Middle East, and Europe. Among those from Western-Anglo countries, smokers were expected to report worse psychological health than non-smokers, especially on self-reported anxiety (consistent with previous findings; see review by Parrott, 2006), whereas no difference was anticipated between smokers and non-smokers among those from the other countries (consistent with the hypothesis of minimal selection bias for smokers with poorer psychological health in those regions).

\section{Method}

\section{Participants}

University students were recruited from the Bond University campus through posters and by individual approach. A total of 147 students participated, including 65 from WesternAnglo countries (Australia, Canada, U.S.) and 82 from diverse other countries in the following regions: Asia (China, India, Japan, Malaysia, Philippines, South Korea, Taiwan, Thailand), Latin America (Brazil, Chile, Ecuador, Mexico, Paraguay), Middle East (Kuwait, Saudi Arabia), and Europe (France, Germany, Netherlands, Sweden). The non-Australian students ( $n=89$ ) were all "study abroad” (i.e., exchange) students. There were 96 non- 
smokers, defined as those who currently do not smoke, and 51 smokers, defined as those who currently smoke cigarettes every day. Among the Western-Anglo sample, 43 were nonsmokers and 22 were smokers; among the non-Anglo sample, 53 were non-smokers and 29 were smokers. Ages ranged from 18 to 52 years $(M=24.66, S D=7.03)$. A monetary incentive of \$10 was given upon the return of each completed questionnaire packet, ensuring a high response rate. The project received full approval from the Bond University Human Research Ethics Committee prior to data collection.

Procedure

A research station was set up in a public place at the Bond University campus. This included a desk for the researchers during specified days and times for participant recruitment, questionnaire distribution and returns to the drop-box. Recruitment occurred through posters set up around campus and direct approach. Both types of recruitment offered participants a monetary incentive of $\$ 10$ to participate, and included brief details of the study as well as where and when the research station would be set up. Guidelines were communicated to each participant, including the requirement to be 18 years of age to take part in the study, and that they were free to discontinue their participation at any point without penalty. Participants either completed their questionnaire at that time, or took the questionnaire away with them and returned it to the research station during one of the specified times of operation. The monetary incentive was given to the participant upon return of their questionnaire. All questionnaires were placed directly into the box by the participants in an unmarked envelope to ensure their anonymity.

\section{Materials}

A brief demographic constructed for the purposes of the present study asked for the participants' age, sex, country where they spent most of their life so far, and the number of cigarettes smoked each day. Participants were also asked "What kind of attitude do you think 
most people have towards smoking in your country?” to be rated on a 5 point Likert scale, with higher ratings indicating greater acceptance of smoking. Participants were asked not to supply their name or any other identifying details in order to maintain their anonymity.

The Depression Anxiety Stress Scales (DASS 21 , Lovibond \& Lovibond, 1995) form a 21 item, self report questionnaire assessing depression, anxiety and stress, with responses indicated by participants on a four point Likert scale ranging from 1 ("Did not apply to me at all”) to 4 (“Applied to me very much, or most of the time”). Each scale consists of seven items. Sample items include “I felt life was meaningless” for the depression scale, “I experienced trembling” for the anxiety scale, and "I found it difficult to relax" for the stress scale. Participants are instructed to answer items according to feelings they have had during the past week. Research on the reliability of the scales with a large community sample has reported Cronbach alphas at .94 for depression, .87 for anxiety and .91 for stress (Antony, Bieling, Cox, Enns \& Swinson, 1998). The scales were also shown to have adequate concurrent validity with other psychological measures. The anxiety scale correlated with the Beck Anxiety Inventory at $r=.85$, and the depression scale correlated with the Beck Depression Inventory at $r=.79$. In the present study, Cronbach alphas for each scale were.89 for depression, .82 for anxiety, and .80 for stress.

Results

A t-test was conducted to compare those from Western-Anglo countries with those from the other countries on responses to the question "What kind of attitude do you think most people have towards smoking in your country?” As expected the ratings for social acceptability of smoking were significantly lower among those from Western-Anglo countries $(M=2.63, S D=1.29)$ than among those from the other countries $(M=3.29, S D=2.33)$, $t(138)=2.04, p=.04$. The number of cigarettes smoked per day was also compared between smokers from Western-Anglo and the other countries because if these were different then 
differences in degree of nicotine intake might conceivably account for any differential findings on anxiety, depression or stress for smokers versus non-smokers from the two samples. However, our two samples of smokers both reported smoking a near-identical average of 9-10 cigarettes per day.

A multivariate analysis of covariance (MANCOVA) was conducted on the anxiety, depression, and stress scores, with country of origin (Western-Anglo vs. Other) and smoker status (smoker vs. non-smoker) as the independent variables and age and sex as covariates. Results showed the predicted multivariate country of origin X smoker status interaction using Pillai's trace, $F(3,139)=2.65, p=.05$. There was also a significant multivariate main effect of country of origin, $F(3,139)=8.83, p<.001$. By contrast, the multivariate main effect of smoker status was not significant, $F(3,139)=1.82, p=.15$.

Univariate analysis revealed that the country of origin X smoker status interaction was significant only for anxiety, $F(1,141)=4.13, p=.04$. As predicted, in the Western-Anglo sample, smokers reported significantly higher levels of anxiety $(M=10.64, S D=9.25)$ than non-smokers did $(M=6.65, S D=6.17), t(64)=2.02, p=.047$. By contrast, in the sample from other countries, smokers $(M=14.90, S D=8.12)$ and non-smokers $(M=15.77, S D=$ 8.44) did not differ in anxiety level, $t(81)=0.30$ Univariate analysis also showed that the students from Western-Anglo (English-speaking) countries scored significantly lower on depression, anxiety, and stress than did the students from non-English-speaking countries of origin: depression, $F(1,141)=19.88, p<.001$; anxiety, $F(1,141)=21.7, p<.001$; stress, $F(1$, $141)=8.81, p=.004$. These differences were expected due to the challenges inherent in attending university classes in a different linguistic and cultural environment for the students from non-Anglo backgrounds. Note that the higher anxiety scores for those from non-Anglo countries $(M=15.46, S D=8.29)$ compared to those from Western-Anglo countries 
$(M=8.00, S D=7.52)$ did not reflect a ceiling effect on anxiety scores because scores on the anxiety scale (like the other two scales) can go as high as 21 . Thus the country of origin $X$ smoker status interaction, which was significant only for anxiety, cannot be interpreted as reflecting a mere ceiling effect for this reason.

\section{Discussion}

As predicted, in the Western-Anglo sample smokers reported significantly higher levels of anxiety than non-smokers did, consistent with previous findings of studies conducted in Western-Anglo countries (see review by Parrott, 2006). However, no differences were found between smokers and non-smokers in the sample from other countries. The present findings thus do not support Parrott's conclusion that the higher levels of anxiety commonly reported among smokers than among non-smokers are attributable solely to physiological effects of nicotine dependence and withdrawal. In the present study, both smoker samples reported smoking an average of 9-10 cigarettes per day, thus indicating similar levels of nicotine intake in the two samples, yet differences in anxiety between smokers and nonsmokers were only found in the Western-Anglo sample. The present findings thus appear to support the hypothesis of a selection bias for smokers with more psychological difficulties occurring in countries such as the U.S., Canada and Australia where smoking has become increasingly stigmatized in recent years. In other countries where smoking is not so stigmatized, there is likely to be far less selection bias toward smokers with psychological difficulties, so the differences in anxiety levels commonly reported between smokers and nonsmokers in Western-Anglo samples may be absent. In other words, where smoking is relatively more culturally accepted as a "normal” adult activity, smokers and non-smokers are not so likely to be psychologically different on average because without strong pressures to quit, differences in smoker status do not emerge between those with psychological difficulties such as anxiety, who find it relatively harder to quit (Grant, Hasin, Chou, Stinson \& Dawson, 
2004; Parrott, 2006; Schumann, Hapke, Meyer, Rumpf, \& Ulrich, 2004; Schmitz, Kruse \& Krugler, 2003), and those without such difficulties. The greater difficulty in quitting smoking among those with anxiety or depression has often been attributed to the self-medicating effects of nicotine, i.e., the anxiolytic and antidepressant effects of the drug (see Parrott, 2006). Indeed, the anxiolytic effect of smoking has long been reported to be the most commonly cited motive given by smokers themselves to explain their habit (e.g., Jaffe \& Jarvik, 1978).

A caveat is that the present study examined foreign exchange students, leaving open the possibility of finding different results when smokers and non-smokers are compared within their home countries - a possible topic for future research investigation. Further, the present study simply compared smokers and non-smokers from Western-Anglo versus “Other” countries, ignoring any variation among the latter - which surely exists and would be interesting to examine in future work with larger and more representative samples. Nevertheless the present findings are important as they appear to suggest that societal and cultural factors can impact upon relationships that are commonly interpreted to have a simple basis in psychopathology or psychobiology, in this case the relationship between smoking and psychological health. 


\section{References}

Antony, M. M., Bieling, P. J., Cox, B. J., Enns, M. W., \& Swinson, R. E. (1998). Psychometric properties of the 42-Item and 21-Item versions of the Depression Anxiety Stress Scales in clinical groups and a community sample. Psychological Assessment, 10(2), 176-181.

Australian Institute of Health and Welfare (AIHW). (2002). 2001 National Drug Strategy Household Survey: State and Territory supplement. Canberra: AIHW.

Centers for Disease Control and Prevention (CDC). (2004). Prevalence of Cigarette Use Among Fourteen Racial/Ethnic Populations - United States, 1999-2001. Morbidity and Mortality Weekly Report (MMWR), 53, 49-52.

Chassin, L., Presson, C. C., Sherman, S. J., \& Kim, K. (2003). Historical changes in cigarette smoking and smoking-related beliefs after 2 decades in a midwestern community. Health Psychology, 22(4), 347-353.

Grant, B. F., Hasin, D. S., Chou, S. P., Stinson, F. S., \& Dawson, D. A. (2004). Nicotine dependence and psychiatric disorders in the United States. Archives of General Psychiatry, 61(11), 1107-1115.

Hersey, J. C., Niederdeppe, J., Evans, W. D., Nonnemaker, J., Blahut, S., Holden, D., Messeri, P., \& Haviland, M. J. (2005). The theory of ‘truth’: How counterindustry media campaigns affect smoking behaviour among teens. Health Psychology, 24(1), 2231.

Hughes, J. R. (1993). Pharmacotherapy for smoking cessation: Unvalidated assumptions, anomalies and suggestions for further research. Journal of Consulting and Clinical Psychology, 61, 751-760.

Hughes, J. R., \& Brandon, T. H. (2003). A softer view of hardening. Nicotine \& Tobacco Research, 6, 961-962. 
Jaffe, J.H., \& Jarvik, M.E. (1978). Tobacco use and tobacco use disorder. In M.A. Lipton, A. DiMascio \& K.F. Killam (Eds.), Psychopharmacology: A generation of progress (pp. 1665-1676). New York: Raven Press.

Lovibond, P. F., \& Lovibond, S. H. (1995). Manual for the Depression Anxiety Stress Scales (2 $2^{\text {nd }}$ Ed.). Sydney: Psychology Foundation.

Lyvers, M., Thorberg, F. A., Dobie, A., Huang, J., \& Reginald, P. (2006). Mood and Relationship Correlates of Heavy Smoking Across Cultures. Presented at the International Congress of the International Association for Cross-Cultural Psychology (IACCP), Spetses, Greece, July 2006.

McVey, D., \& Stapleton, J. (2000). Can anti-smoking television advertising affect smoking behaviour? Controlled trial of the Health Education Authority for England's antismoking TV campaign. Tobacco Control, 9, 273-282.

Mitchell, E., \& Sanders, J. (2004). Current tobacco smoking by the New South Wales population and the consequences for health. New South Wales Public Health Bulletin, $15,87-91$.

Parrott, A.C. (2006). Nicotine psychobiology: How chronic-dose prospective studies can illuminate some of the theoretical issues from acute-dose research. Psychopharmacology, 184, 567-576.

Pierce, J. P., Gilpin, E. A., Emery, S. L., White, M. M., Rosbrook, B., \& Berry, C. C. (1998). Has the California Tobacco Control Program reduced smoking? Journal of the American Medical Association, 280, 893-899.

Schmitz, N., Kruse, J., \& Kugler, J. (2003). Disabilities, quality of life, and mental disorders associated with smoking and nicotine dependence. American Journal of Psychiatry, 160, $1670-1676$. 
Schumann, A., Hapke, U., Meyer, C., Rumpf, H., \& Ulrich, J. (2004). Prevalence, characteristics, associated mental disorders and predictors of DSM-IV nicotine dependence. European Addiction Research, 10, 29-34.

Trosclair, A., Husten, C., Pederson, L., \& Dhillon, I. (2002). Cigarette smoking among adults - United States 2000. Morbidity and Mortality Weekly Report, 51, 642-645.

Victorian Smoking and Health Program Australia (Quit Victoria). (1995). Tobacco in Australia: Facts and Issues. Australia: ASH Ltd.

World Health Organization (WHO). (2002). Tobacco Atlas. Geneva: World Health Organization. 